\title{
COMPETITION BETWEEN THREE LINES OF DROSOPHILA MELANOGASTER
}

\author{
J. S. GALE \\ A.R.C. Unit of Biometrical Genetics, Department of Genetics, \\ University of Birmingham
}

Received 20.v.64

\section{INTRODUCTION}

THE term " competition" has been used by various authors to cover a wide range of different phenomena, so that many definitions of this term exist in the literature (Birch, 1957; Milne, 1961). In the present discussion we shall use the term in the sense proposed by Milne (I $196 \mathrm{I}$ ), " competition is the endeavour of two (or more) animals to gain the same particular thing, or to gain the measure each wants from the supply of a thing when that supply is not sufficient for both (or all)". Thus, for example, we shall say that two strains A, B of Drosophila larvæ are competing for food if in a mixed culture of $\mathrm{A}$ and $\mathrm{B}$, food is present in insufficient quantity for all the larvæ present to complete their life cycles. If individuals of strain $\mathrm{A}$ are, on average, more successful in obtaining the food present than are individuals of strain B, strain A individuals will be regarded, on average, as competitively superior to strain B individuals. Bakker (196I) has shown that the competitive superiority of wild type over Bar larvæ is due to the fact that wild type larvæ feed more rapidly than do Bar larvæ, and so obtain a disproportionately large amount of the limited quantity of food available. The results given below indicate that, as expected, competition for food is at least a major component of competition between the three lines of Drosophila under investigation, but do not exclude the possibility that other types of competition are also occurring.

If we have two strains $A$ and $B$, of which $A$ is competitively superior, and raise the strains in both pure and mixed culture by placing a fixed number (say 100) of larvæ in a tube containing food, then if the food is present in limiting quantity the biomass of A per initial A larva resulting at the end of competition should be higher in mixed than in pure culture, whereas that for B should be lower in mixed than in pure. For, in pure culture of A, every A larva is competing with, in our example, 99 strong competitors whereas in a $50 / 50$ mixture of $A$ and B every A larva is competing with 49 strong but 50 weak competitors, so that, on average, an A larva will obtain more food in mixed than in pure culture. Precisely the reverse holds for B. In practice, it is convenient to count the number of adults emerging rather than the biomass produced. If the percentage survival to adulthood of A larvæ is higher in mixed than in pure culture, whereas the reverse holds for B, and in addition these differences between pure and mixed cultures disappear when food is present in abundant quantity, a competitive difference between $\mathrm{A}$ and $\mathrm{B}$ will have been demonstrated. 
Suppose, however, that line A shows a higher viability than B in mixed cultures, owing to the superior competitive ability of A. It does not necessarily follow that A are fitter than B in mixed cultures, for the $A$ adults which emerge, while greater in number than the $B$ adults, could be so inferior in fitness to the B flies as to outweigh their competitive advantage. In order to show that the superior competitive ability of A is biologically meaningful, it is necessary to compare the fitness of A and B flies emerging from competition vials. These flies will be subsequently referred to as " ex-competitors" and experiments will be described to compare $\mathrm{A}$ and $\mathrm{B}$ ex-competitors with reference to their ability to give rise to fertile matings, the hatchability of the eggs they produce, and the number of offspring produced per mating. In addition, the competitive abilities of the larval progeny of ex-competitors has been investigated.

Given that a competitive difference has been demonstrated, it is possible to some extent to predict the effects of competition in situations rather different from those in which competition was first shown. Thus we might vary the initial composition of the mixed culture, for example by having initially $2 A: I B$ and $I A: 2 B$ instead of $I A: I B$. Equally, after we have examined the output of three lines A, B, and C in pure culture and in 2-way mixed culture (A with $B, A$ with $C$ and B with $\mathrm{C}$ ), then if we have a fairly simple system of competition we should be able to make a quantitative prediction of what will happen in 3-way mixed cultures (A, B and C together). Such a prediction would of course not be possible if there were complicated interactions between competing lines such that the results obtained when 3 lines compete bore little relation to those obtained when 2 lines compete. A situation of this kind would arise, for example, if A were competitively superior to B and B to C but A were not superior to C. Experiments designed to investigate these situations will be described.

\section{MATERIALS AND METHODS}

The lines used were Oregon $(O r)$ and two selection lines carrying the markers dumpy $(d p)$ and vestigial $(v g)$ respectively. We are indebted to Professor Thoday for supplying these last two lines, which, although not as highly inbred as Oregon, gave a consistent performance with regard to competition during the experiments. Following the technique devised by Bakker (196I), the flies were made to lay eggs in large quantities in the course of $3-4$ hours, as follows. About 80 pairs of flies of a given line are shaken into $x / 3$ pint milk bottles containing oatmeal medium well covered with yeast and left in the incubator at $25^{\circ} \mathrm{C}$. for 4 days. After 2 days the surface of the medium is completely covered with eggs and further laying is inhibited. During days 3-4 females accumulate large numbers of unlaid eggs. The flies are then transferred to tubes containing oatmeal medium and a little yeast, a plastic strip coated with a starch-charcoal gel having first been placed in each tube and kept in position by being pushed into the oatmeal. Irrespective of the line used, flies begin laying on the gel about $\frac{1}{2}$ hour after transfer. Laying reaches a maximum between the second and third hours and is normally complete at 4 hours after transfer. The eggs are then transferred in groups of 20 to petri dishes containing agar and incubated at $25^{\circ} \mathrm{C}$. A small proportion of the eggs hatch almost at once, but the bulk of the eggs hatch 21-22 hours after laying. By this time, the larvæ derived from 
the early hatchers can easily be recognised by their large size. Such larvæ were not used in any experiments. It will be shown below that the median hatching time is almost identical for the three lines $O r, d p$ and $v g$. Thus, provided we discard the early larvæ, the technique used enables us to obtain larvæ of approximately the same age.

Larvæ were transferred to experimental vials by means of a flattened wire mounted in a holder. The vials each contained a known volume of medium consisting of $10 \mathrm{gm}$. dead yeast, $19 \mathrm{gm}$. Spanish agar and $10 \mathrm{ml}$. 10 per cent. Nipagin per litre of distilled water, which had been heated in a water bath for 40 minutes and autoclaved. It was found convenient to adjust the food level by varying the volume of medium. It was thought inadvisable to adjust the food level by varying the concentration of yeast, firstly because the agar may well provide nutrients essential for development of the fly and secondly because doubling the concentration of yeast, for example, will presumably more than double the effectively available food, since at high concentration less energy is expended by the larva in its search for food. Over the volumes of medium used, the larvæ were able to work the medium thoroughly, so that all food present was in fact available. Hence doubling the volume of medium will double the food available.

\section{EVIDENCE FOR COMPETITIVE DIFFERENCES BETWEEN THE LINES}

The following experiment was carried out in 5 randomised blocks. Each block comprised 21 tubes, 7 at each of 3 food levels, namely 4 ,

TABLE 1

Number of adults emerging

\begin{tabular}{|c|c|c|c|c|c|c|c|c|c|c|c|c|c|}
\hline \multirow{2}{*}{$\begin{array}{l}\text { Food } \\
\text { Volume }\end{array}$} & \multirow{2}{*}{ Block } & \multicolumn{12}{|c|}{ Initial composition of tube } \\
\hline & & $9 \circ \mathrm{Or}$ & $90 d p$ & $9 \circ \mathrm{vg}$ & \multicolumn{2}{|c|}{$\begin{array}{c}45 O r \prime \\
45 d p\end{array}$} & \multicolumn{2}{|c|}{$\begin{array}{l}45 \mathrm{Orl} \\
45 \mathrm{vg}\end{array}$} & \multicolumn{2}{|c|}{$\begin{array}{l}45 d p / \\
45 \mathrm{vg}\end{array}$} & \multicolumn{3}{|c|}{$30 \mathrm{Or} / 30 \mathrm{dp} / 3 \mathrm{O} \mathrm{gg}$} \\
\hline \multirow{6}{*}{$4 \mathrm{ml}$} & & & & & & $d p$ & Or & vg & $d p$ & $v g$ & Or & $d p$ & \\
\hline & 1 & 0 & 2 & I & o & 5 & o & 3 & (o) & (1) & 2 & o & 2 \\
\hline & 2 & 3 & 3 & 0 & o & 4 & I & 0 & I & o & o & o & 2 \\
\hline & $\begin{array}{l}3 \\
4\end{array}$ & $\begin{array}{l}4 \\
2\end{array}$ & $\begin{array}{l}y \\
2\end{array}$ & 0 & 0 & I & 2 & 1 & 0 & 1 & 0 & 0 & $\begin{array}{l}3 \\
0\end{array}$ \\
\hline & 5 & 0 & I & 0 & o & o & 0 & 2 & o & o & 0 & I & 2 \\
\hline & Total & 9 & 17 & 2 & I & 15 & 4 & 7 & I & 3 & 3 & 2 & 9 \\
\hline \multirow{6}{*}{$6 \mathrm{ml}}$. & I & 26 & 23 & 8 & 2 & 9 & (2) & (11) & 6 & 8 & 5 & 10 & 6 \\
\hline & 2 & 15 & 26 & 3 & 5 & 10 & 2 & 12 & 8 & 13 & 0 & 5 & 5 \\
\hline & 3 & 35 & 28 & 13 & I & 19 & 3 & 10 & 8 & 7 & 3 & 9 & 8 \\
\hline & 4 & 4 & 21 & 7 & 2 & 8 & I & 6 & 5 & 5 & 2 & 5 & 8 \\
\hline & 5 & 14 & 22 & 9 & I & 18 & 0 & 14 & 5 & 7 & I & 7 & 7 \\
\hline & Total & 94 & 120 & $4^{\circ}$ & II & 64 & 8 & 53 & 32 & 40 & II & 36 & 34 \\
\hline \multirow{6}{*}{$8 \mathrm{ml}}$. & I & 52 & 46 & 22 & 27 & 20 & 13 & 18 & 17 & 12 & 9 & 15 & 12 \\
\hline & 2 & 57 & 55 & 28 & I 5 & 23 & 28 & 20 & 24 & 13 & 26 & 10 & 12 \\
\hline & 3 & 46 & 44 & 24 & 10 & 29 & 21 & 14 & 20 & 17 & 10 & II & 17 \\
\hline & 4 & 32 & 29 & 29 & 5 & 20 & 5 & I6 & 18 & I 8 & 3 & $I_{3}$ & 8 \\
\hline & 5 & 18 & $4^{\circ}$ & 25 & 7 & 24 & 3 & 19 & 13 & II & 2 & 11 & \\
\hline & Total & 205 & 214 & 128 & 64 & II 6 & 70 & 87 & 92 & 71 & $5^{\circ}$ & 60 & 65 \\
\hline
\end{tabular}


6 and $8 \mathrm{ml}$. of medium. As go larvæ were placed in each tube, these food levels correspond to $4 / 9,6 / 9$ and $8 / 9 \mathrm{mg}$. of yeast per larva. In one block, $2 \mathrm{ml}$. of medium were used, but no adults emerged, so this food level was discontinued. A set of 7 tubes was made up as follows:(I) contained $90 \mathrm{Or}$ larvæ, (2) $90 \mathrm{dp}$, (3) $90 \mathrm{vg}$, (4) $45 \mathrm{Or} / 45 \mathrm{dp}$, (5) 45 Or/45 vg, (6) $45 d p / 45 \mathrm{vg}$, (7) $30 \mathrm{Or} / 30 \mathrm{dp} / 30 \mathrm{vg}$. Table I gives the

TABLE 2

Differences in survival in pure and mixed cultures

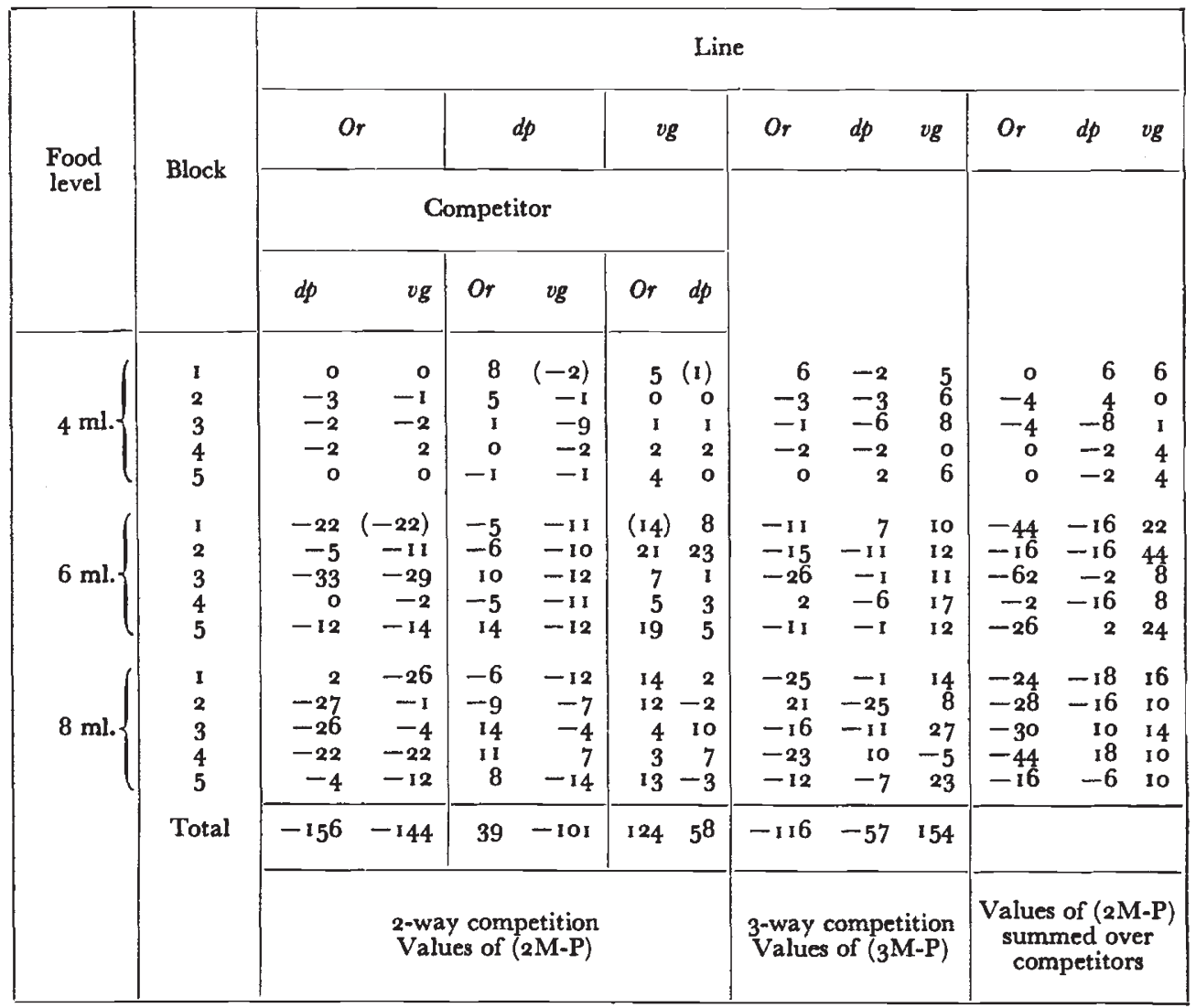

number of adults emerging from each type of tube. (In the first block, the values shown in brackets represent tubes which were missing owing to a shortage of larvæ; averages over the other blocks have been inserted.)

Considering first the 2-way competition tubes, we note that for a given line there were initially 90 larvæ in the pure and 45 in the mixed cultures. We shall write (P) and (M) for the yields in pure and mixed culture, respectively. The value of (2M-P) is therefore a measure of competition, a positive value indicating a strong competitor, a negative value a weak competitor. For the 3-way 
competition, there were only 30 larvæ of each line in mixed cultures, so that $(3 \mathrm{M}-\mathrm{P})$ is the appropriate measure of competition. Values are given in table 2.

In the absence of competition, (2M-P) values should be positive and negative equally frequently, and similarly for ( $3 \mathrm{M}-\mathrm{P})$ in the 3-way competition. We can thus carry out a simple test of significance based on sign alone. Since for a given line the corresponding values of (2M-P) for the two competitive situations are not independent, being based on the same value of $(P)$, we should base our test on the mean or sum over competitors. Ignoring the zeros, we thus have

\begin{tabular}{|c|c|c|c|c|}
\hline Line & No. of $+\mathrm{s}$ & No. of $-\mathrm{s}$ & $\chi_{[1]}^{2}$ & $\mathbf{P}$ \\
\hline $\begin{array}{l}\text { Or } \\
d p \\
v g\end{array}$ & $\begin{array}{r}0 \\
5 \\
14\end{array}$ & $\begin{array}{r}12 \\
10 \\
0\end{array}$ & $\begin{array}{r}12 \cdot 00 \\
1.67 \\
14.00\end{array}$ & $\begin{array}{l}<0.1 \text { per cent. } \\
20-10 \text { per cent. } \\
<0.1 \text { per cent. }\end{array}$ \\
\hline
\end{tabular}

Clearly, we have strong evidence for the presence of competition, $v g$ consistently having a higher survival rate in mixed than in pure culture whereas the reverse holds for Or. It is also clear from table 2 that $v g$ is a better competitor than $d p$ or Or. For competition between $d p$ and $O r$, the $d p$ results are rather irregular, but since $O r$ consistently falls in viability ( $\mathrm{I}+$ to $\mathrm{II}-\mathrm{s}, \chi_{[1]}^{2}=8 \cdot 5, \mathrm{P}=\mathrm{I}-0 . \mathrm{I}$ per cent.) when competing with $d p$ and $d p$ on average rises in viability, we can conclude with confidence that $d p$ is superior to $O r$. Independent evidence for this will be given below.

Thus we may conclude that $v g$ is competitively superior to both $d p$ and $O r$, and that $d p$ is superior to Or. Consistent with this view is the fact that $v g$ does very much better in competition with $O r$ than in competition with $d p$. Rather surprisingly, however, Or does no worse in competition with $v g$ than in competition with $d p$.

In addition, the 3-way competition results follow the general pattern of the 2-way. Thus in the 3-way vg gains from the competition situation, $d p$ loses somewhat and Or loses very considerably.

The same pattern of results holds at all food levels.

Perhaps the most striking result is that $v g$, which the lowest viability in pure culture, is the line that profits most from the mixed situation. Clatworthy and Harper ( 1962 ) have described an analogous situation in duckweed.

It is difficult from this experiment to make quantitative comparisons of 2-way and 3-way competition because, for example, in the 2-way cases $O r$ is competing against an equal number of competitors of one of the other lines, whereas in the 3-way cases 30 Or are competing against 6 o non-Or competitors. To elucidate this situation the following experiment was carried out. 


\section{EFFECT OF VARYING THE INITIAL PROPORTION OF COMPETING LINES}

This experiment consisted of 4 blocks with ro tubes per block. The ro tubes each contained $6 \mathrm{ml}$. of medium (2/3 mg. yeast per larva) and were constituted as follows:-(I) containing 9o Or, (2) 90 $d p$, (3) $90 \mathrm{vg}$, (4) 6o Or/30 dp, (5) 6o dp/30 Or, (6) 6o Or/30 vg, (7) 6o vg/ $30 \mathrm{Or},(8) 60 \mathrm{dp} / 30 \mathrm{vg}$, (9) $60 \mathrm{vg} / 30 \mathrm{dp}$ and (г) $30 \mathrm{Or} / 30 \mathrm{dp} / 30 \mathrm{vg}$, the numbers referring to larvæ. As before, the number of adults emerging from each tube was scored. Results are given in table 3.

TABLE 3

Number of adults emerging under different competitive situations

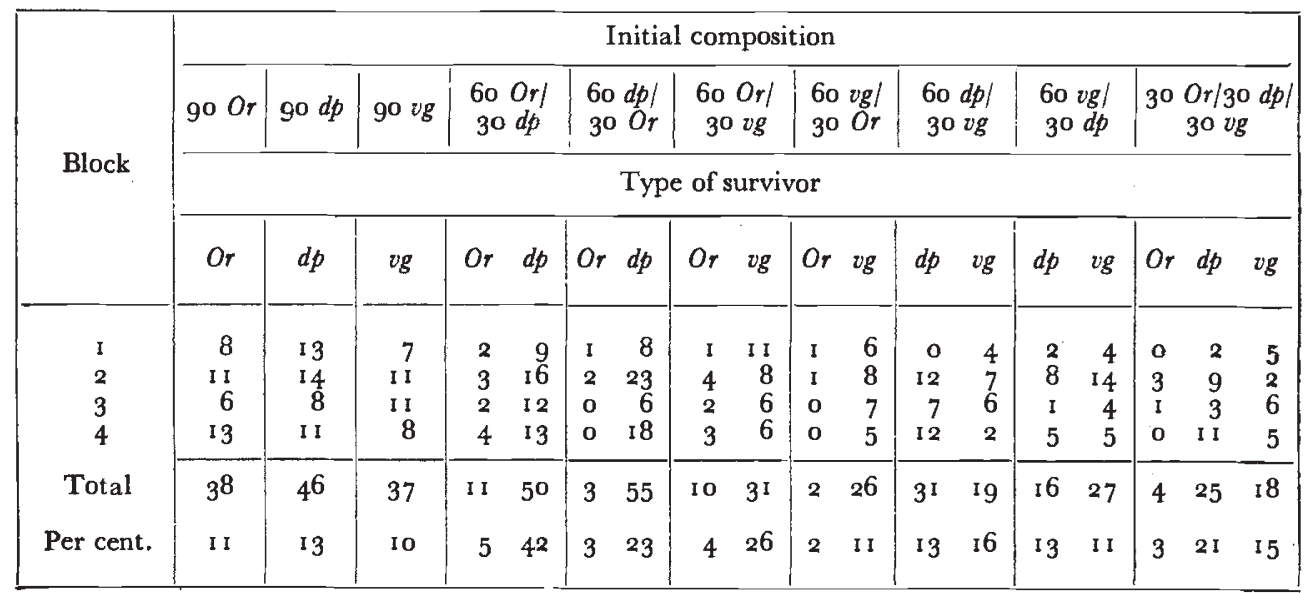

Apart from one anomalous result, namely that the percentage survival of $d p$ in competition with $v g$ is the same as in pure culture, the results are in very good agreement with those obtained in the previous experiment. That is, Or has a lower viability in mixed than in pure cultures, $v g$ has a higher viability in mixed than in pure and $d p$ has a higher viability when it is competing with $O r$ than it has in pure culture.

It was suggested in the Introduction that, provided we know which of two lines is the stronger competitor, it should be possible to make at least a qualitative prediction of the effects of varying the initial composition of the mixture. For, if a strong competitor $\mathrm{A}$ is in competition with a weak competitor $B$, then is we vary the initial composition of the mixture, the viability of both $\mathrm{A}$ and $\mathrm{B}$ should rise as the proportion of $\mathrm{A}$ in the initial mixture is decreased, i.e. as we increase the initial proportion of weak competitors, all larvæ are facing milder and milder competition. Thus, on comparing pure cultures 
and the various types of mixed culture with one another we should expect:-

(1) The percentage survival of $O r$ should fall as the proportion of $O r$ in the initial mixture falls.

(2) The percentage survival of $v g$ should rise as the proportion of $v g$ in the initial mixture falls.

(3) The percentage survival of $d p$ should rise as the proportion of $d p$ in a mixture of $d p / O r$ falls and should fall as the proportion of $d p$ in a mixture of $d p / v g$ falls.

Results are given in table 4 the $45 / 45$ results being taken from the previous experiment. As the viability of $\mathrm{Or}$ seems for some reason to

TABLE 4

Effect on survival of varying the initial composition

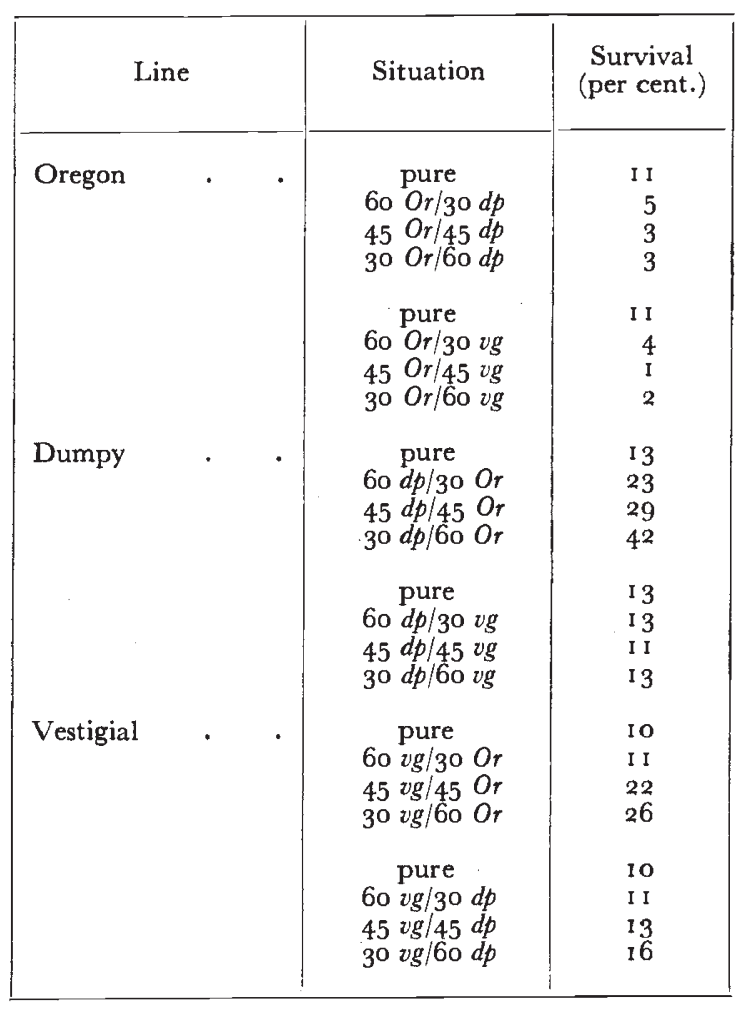

have fallen after block 3 of the earlier experiment both in pure and mixed cultures (this happened at the same time in the stock culture bottles, in which the flies had been maintained on oatmeal medium, and so is not related to the conditions of our experiment as such), we shall use the results of blocks 4 and 5 only, since the viability of $O r$ in those blocks seems about the same as in the experiment being described. 
Apart from the behaviour of $d p$ in competition with $v g$, the results are in good agreement with expectation. Since the competitive abilities of $d p$ and $v g$ are not too far apart, the anomalous behaviour of $d p$ is not altogether surprising. We can obtain a simple test of significance based on mixed cultures only by adding together the percentage survivals of the two competitors in a given situation and ranking these compounded survival rates. From table 4 we have the data given in table 5 .

On our theory, these compounded survivals should be ranked I, 2, 3 in all three sets of situations. This has in fact happened, apart from the tied result in the competition between $d p$ and $v g$. We shall calculate the probability of obtaining as extreme or more extreme a result as that observed, on the null hypothesis that the compounded survivals are ranked at random. Since there are 6 ways of ordering

TABLE 5

Compounded survival rates

\begin{tabular}{|c|c|c|c|c|c|}
\hline Situation & $\begin{array}{l}\text { Compounded } \\
\text { survival }\end{array}$ & Situation & $\begin{array}{l}\text { Compounded } \\
\text { survival }\end{array}$ & Situation & $\begin{array}{c}\text { Compounded } \\
\text { survival }\end{array}$ \\
\hline $\begin{array}{ll}60 & O r / 30 \\
45 & O r / 45 d p \\
45 & 0 r / 60 d p\end{array}$ & $\begin{array}{l}47 \\
32 \\
26\end{array}$ & $\begin{array}{ll}60 & 0 r / 30 \\
45 & O r / 45 \\
45 & \text { vg } \\
30 & 0 r / 60 \text { vg }\end{array}$ & $\begin{array}{l}30 \\
23 \\
13\end{array}$ & $\begin{array}{l}60 d p / 30 \text { vg } \\
45 d p / 45 v g \\
30 d p / 60 \text { vg }\end{array}$ & $\begin{array}{l}29 \\
24 \\
24\end{array}$ \\
\hline
\end{tabular}

3 objects, then for $O r / d p$ and $O r / v g$ competition, we have a probability of $\mathrm{I} / 6$ in each case of obtaining our observed results, which represent the most extreme case possible, since we are, of course, carrying out a one-tail test. With regard to the tie, the case most favourable to the null hypothesis would be obtained if we regarded the tie as in fact representing a I, 3, 2 ranking, in which case results as extreme or more so would be $(a)$ I, 2, 3 or $(b)$ I, 3, 2 or $(c)$ 2, I, 3 since I, 2, 3 is the most extreme case and the other two cases have one result in the extreme position and the other two inverted. Out of $6^{3}=216$ possible results for the three sequences taken together we have $3 \times 2=6$ where (b) or $(c)$ occur in one set of situations together with I, 2, 3 in the other two sets and one case where $1,2,3$, occurs in all three sets, whence the probability $\mathrm{P}$ of getting as extreme or more extreme result is $(6+\mathrm{I}) / 2 \mathrm{I} 6$ $=3.24$ per cent. This, of course, assumes the tie represents a $\mathrm{I}, 3,2$ ranking. If, in fact, the ranking were $\mathrm{I}, 2,3 \mathrm{P}$ would be $\mathrm{I} / 2 \mathrm{I} 6=0 \cdot 46$ per cent. The true value of $\mathrm{P}$ lies between these two extremes. Hence we may conclude that the rankings depart significantly from randomness in the direction indicated by our theory.

\section{THREE-WAY COMPETITION}

If we assume that competition operates in a simple manner, it should be possible to predict the 3-way results, knowing only results 
TABLE 6

Data relating to prediction of 3-way competition results

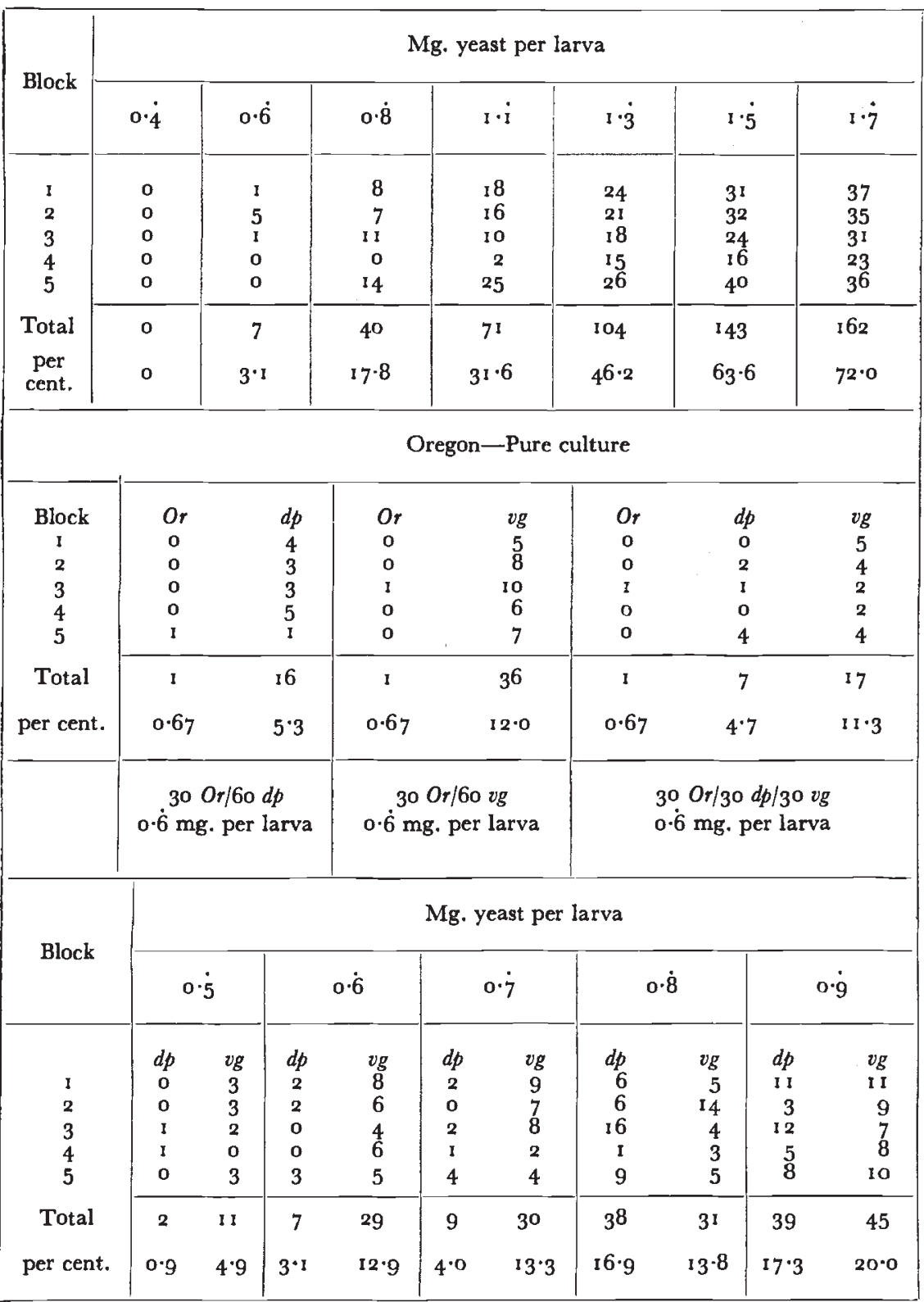

in pure culture and in 2-way competition, provided we assume that competition is, in the main, for food. In order to investigate this possibility, an experiment was carried out in 5 randomised blocks, each block consisting of 16 tubes constituted as follows:-eight tubes 
each contained 45 Or larvæ at various food levels, which rose in steps of I $\mathrm{ml}$. from $2 \mathrm{ml}$. to $8 \mathrm{ml}$, thus corresponding to $0 \cdot \dot{4}, 0 \cdot \dot{6}, \ldots, \mathrm{I} \cdot \dot{7} \mathrm{mg}$. of yeast per larva. All other tubes contained go larvæ. Three, all having $6 \mathrm{ml}$. of medium per tube, contained $30 \mathrm{Or} / 6 \mathrm{o} \mathrm{dp}$, $30 \mathrm{Or} / 6 \mathrm{o} \mathrm{vg}$ and $30 \mathrm{Or} / 30 \mathrm{dp} / 30 \mathrm{vg}$ larvæ respectively while the remaining 5 tubes each contained $45 \mathrm{dp} / 45 \mathrm{vg}$ larvæ, the medium rising in steps of I $\mathrm{ml}$. from 5 to $9 \mathrm{ml}$. Results are given in table 6 . It will be seen that yields are low compared to those obtained previously, but the general picture of competition is unaltered. In fact, data on survival of $d p$ and $v g$ in pure culture, which had been obtained together with the data in table 6 as a check on the competitive structure, showed that at $0 . \dot{6} \mathrm{mg}$. yeast per larva the survival rates of $d p$ and $v g$ were $2 \cdot 7$ per cent. and $6 \cdot 2$ per cent. respectively in pure culture. A comparison of these results with those given in table 6 indicates good agreement with earlier results.

For convenience, we shall consider the survival of $\mathrm{Or}$ first, since $\mathrm{Or}$ shows the same survival rate, 0.67 per cent., whether 30 Or are competing against $60 d p$ or $60 \mathrm{vg}$. Thus the predicted survival rate for $O r$ when $30 \mathrm{Or}$ are competing against $30 \mathrm{dp}$ and $30 \mathrm{vg}$ jointly is 0.67 per cent. Now from the survival curve of $O r$ in pure culture, we obtain the amount of yeast per Or larva required to give rise to a 0.67 per cent. survival of $\mathrm{Or}$. On multiplying this value by 30 , we have the amount of yeast taken up in the 3-way competition tubes by the Or larvæ, survivors and non-survivors combined.

In the presence of abundant food, the viability of Or larvæ proved to be 84.86 per cent. (see section 7). The regression of $r$, the probit of the percentage survival of $O r$ in pure culture on $x$, the logarithm of the number of $\mathrm{mg}$. of yeast per larva can therefore be determined from the data given in table 6 , the computations making due allowance for " natural" mortality, that is, the mortality which is not dependent on lack of food, following the procedure given by Finney (1952). The relation between $Y$ and $x$ proved to be

$$
r=4 \cdot 4 \text { I } 65+6 \cdot 3760 x
$$

the estimate of the " natural "viability from the combined data being 84.87 per cent. Corresponding to a survival of 0.67 per cent., which on division by 0.8487 gives 0.78 per cent. with a probit of 2.58 , the log. food level is $-0.287 \mathrm{mg}$./larva, that is, a food level of $0.516 \mathrm{mg}$. per larva. Thus the amount of food taken up by our 30 Or larvæ in 3 -way competition is estimated at $30 \times 0.5 \mathrm{I} 6=\mathrm{I} 5.48 \mathrm{mg}$. Thus of the $60 \mathrm{mg}$. of yeast initially present in the 3 -way competition tubes, 44.52 mg. are left for the $60 d p$ and $v g$ larvæ, so that we have 0.74 mg. yeast per larva of $d p$ or $v g$. We therefore require the survival rates of $d p$ and $v g$ when equal numbers of these larvæ are competing at a food level of 0.73 . We have data for survivals at $0 . \dot{6}$ and 0.7 food levels and may take these as lower and upper limits for our predicted survival rates. We shall multiply these rates by $5^{0}$ to obtain the predicted 
totals in 3-way competition over the 5 blocks, since there were initially 30 larvæ of each line per tube in a given block. We, therefore, have

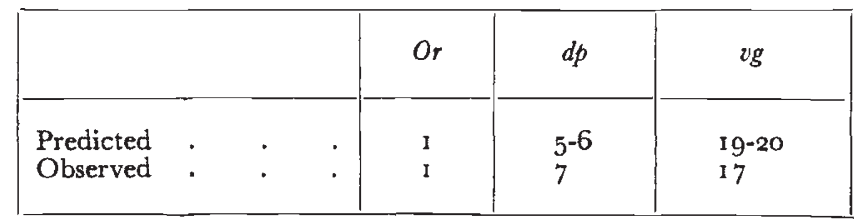

The observed results are in very good agreement with those predicted.

\section{ARE COMPETITIVE DIFFERENCES MERELY A SECONDARY EFFECT OF DIFFERENCES IN HATCHING TIME?}

The technique used for collecting eggs ensures that all 3 lines begin laying at about the same time. If, however, there were gross differences between the lines in their hatching times, the larvæ of different lines would differ in their ages when placed in competition tubes. Bakker (I96I) has shown that a difference of only a few hours in age between larvæ of the competing lines can produce a strong apparent competitive effect.

Superficial observation suggested that no such differences in time of hatching existed in the case of our lines, but to check this, the following experiment was carried out.

Adults of the 3 lines which had started to lay were placed in laying tubes and allowed to lay until each line had laid at least Ioo eggs. This took between 20 and 40 minutes on different occasions. The flies were transferred again to laying tubes and a second and subsequently a third lot of eggs obtained. For each lot, I oo eggs of each line were placed on petri dishes containing agar. Each lot thus constituted a block consisting of 3 petri dishes (one of each line) which were placed in random positions in the incubator.

It had been hoped to determine the mean hatching time for each line by scoring each petri dish at 20-minute intervals over the period of hatching. This proved impracticable, since the period of hatching is very long. In fact, some larvæ hatch within a few hours of laying, as reported also by Bakker, who states that these larvæ come from eggs which have begun to develop in the mother. Such larvæ, which can easily be detected by their large size at a time when the other larvæ are quite small were in any case rejected in all our experiments. However, the bulk of the larvæ emerge 20 hours or later after laying. It was noticed that for $d p$ and $v g, 79$ per cent. or more of the eggs hatched during a period of I hour 20 minutes and that in two of the three blocks $74-76$ per cent. of the $O r$ hatched within such a period. For these reasons the median hatching time, for those eggs which actually hatched, seems the most appropriate parameter to estimate. The starting point was taken as half-way through the laying period. The results are given in table 7. The average median times for $\mathrm{Or}$ 
TABLE 7

Number of eggs (out of IOO) hatching by a given time

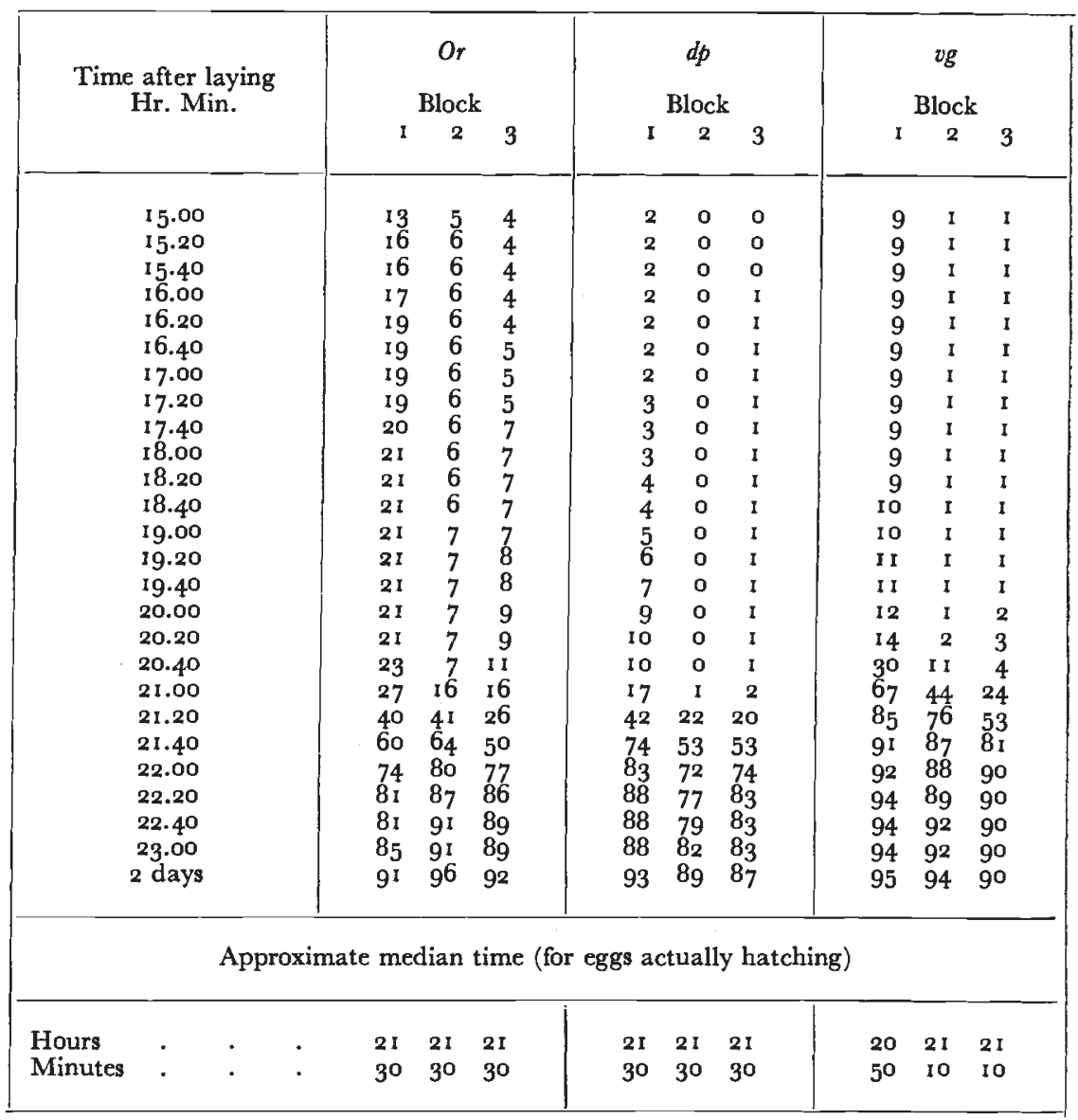

and $d p$ are approximately $2 \mathrm{r}$ hours 30 minutes and that for $v g \mathrm{~g}$ hours 3 minutes, within the limits of the scoring technique used. The differences are thus quite trivial, and our results cannot be attributed to differences in hatching time.

\section{VIABILITIES IN PURE AND MIXED CULTURE WHEN FOOD IS ABUNDANT}

If we are correct in supposing that our competitive differences represent, in the main, differences in feeding rate, then when food is present in abundance the viability of a given line should be the same in mixed as in pure culture. This would not be the case if the differences between pure and mixed cultures represented the effects of the excretory products of one line on another in mixed cultures. To investigate this, an experiment was set up in which the experimental 
tubes contained oatmeal medium covered with an excess of live yeast, thus ensuring abundant food while not preventing the diffusion of possible excretory products. The experiment comprised 4 blocks with 6 tubes per block, the 6 tubes containing $90 \mathrm{Or}, 90 \mathrm{dp}, 90 \mathrm{vg}, 45 \mathrm{Or} / 45$ $d p, 45$ Or/45 vg and $45 d p / 45$ vg larvæ respectively. The results are given in table 8 .

Consider first the comparison between the yield of a line in pure culture and its overall yield in mixed culture. If we sum the yields

TABLE 8

Number of adults emerging when food is abundant

Initial composition of tube

\begin{tabular}{|c|c|c|c|c|c|c|}
\hline Block & $90 \mathrm{Or}$ & $90 d p$ & $90 \mathrm{vg}$ & 45 Or/45 $d f$ & 45 Or/45 vg & $.45 d p / 45 v g$ \\
\hline & & & & Or $d p$ & Or vg & $d p \quad v g$ \\
\hline $\mathbf{I}$ & 73 & 68 & 55 & $293^{1}$ & $43 \quad 3^{6}$ & $\begin{array}{ll}35 & 26\end{array}$ \\
\hline ? & 79 & 68 & $6 \mathrm{I}$ & $40 \quad 34$ & $35 \quad 32$ & $40 \quad 35$ \\
\hline 3 & 80 & 73 & 65 & $\begin{array}{ll}40 & 33 \\
0\end{array}$ & $39 \quad 24$ & $\begin{array}{ll}3^{8} & 31 \\
& 1\end{array}$ \\
\hline 4 & & & 57 & $\begin{array}{l}40 \quad 26 \\
\end{array}$ & $37 \quad 3^{0}$ & $\begin{array}{ll}39 & 36 \\
\end{array}$ \\
\hline Total & 308 & 275 & 238 & 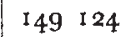 & $154 \quad 122$ & $152 \quad 128$ \\
\hline Per cent. & 86 & $7^{6}$ & 66 & $83 \quad 69$ & $86 \quad 68$ & 8471 \\
\hline
\end{tabular}

TABLE 9

Analysis of yields at high food levels

\begin{tabular}{|c|c|c|c|c|c|}
\hline Item & S.S. & d.f. & M.S. & V.R. & $\mathbf{P}$ \\
\hline $\begin{array}{l}\text { Lines } \\
\text { Blocks } \\
\text { Pure versus Mixed } \\
\text { Error }\end{array}$ & $\begin{array}{r}472 \cdot 8750 \\
45 \cdot 4167 \\
10 \cdot 6250 \\
97 \cdot 3333\end{array}$ & $\begin{array}{r}2 \\
3 \\
3 \\
15\end{array}$ & $\begin{array}{r}236 \cdot 4375 \\
15 \cdot 1389 \\
3 \cdot 5417 \\
6 \cdot 4889\end{array}$ & $\begin{array}{c}36 \cdot 44 \\
2 \cdot 33 \\
<1\end{array}$ & $\begin{array}{l}<0 \cdot I \text { per cent. } \\
20-10 \text { per cent. } \\
\text { Not significant }\end{array}$ \\
\hline
\end{tabular}

of a given line over the two mixed cultures in which it appears, all yields are based on go larvæ. We now have the analysis of variance given in table 9, in which interactions with blocks, which proved to be homogeneous, have been pooled to give a joint error. The Pure versus Mixed mean square is, in fact, numerically smaller than the error mean square and thus obviously not significant.

We can carry out a second analysis, independent of the first, using the mixed culture data only, in order to ascertain whether the yield of a given line in mixed culture varies with the type of competitor present. This analysis is shown in table Io, from which it is seen that the yield of a given line is independent of which of the other two lines is present in the tube in which it is reared. The two analyses, therefore, are in agreement in demonstrating that when food is abundant, the 
viabilities of any one of our three lines are independent of the presence or absence of the others. We conclude that our earlier results cannot be explained in terms of the action of excretory products of one line on another in mixed culture.

TABLE 10

Comparison of yield in different types of mixed culture, at high food levels

\begin{tabular}{|c|c|c|c|c|c|}
\hline Item & S.S. & d.f. & M.S. & V.R. & $\mathbf{P}$ \\
\hline $\begin{array}{l}\text { Within lines, between types } \\
\text { of mixed culture } \\
\text { Error }\end{array}$ & $\begin{array}{l}105 \cdot 6250 \\
229 \cdot 8750\end{array}$ & $\begin{array}{l}3 \\
9\end{array}$ & $\begin{array}{l}35 \cdot 2083 \\
25 \cdot 5417\end{array}$ & $\mathrm{I} \cdot 3^{8}$ & $>20$ per cent. \\
\hline
\end{tabular}

\section{THE FITNESS OF FLIES EMERGING FROM COMPETITION TUBES}

We have measured all our competition effects in terms of the number of adults emerging from mixed culture and in particular have shown that whereas the viability of $v g$ in pure culture was never substantially higher and frequently lower than the viability of $\mathrm{Or}$ in pure culture, the $v g$ line throughout showed a strikingly higher viability than $O r$ in mixed cultures of these two lines. Before, however, we can conclude that $v g$ is the fitter of the two lines in mixed cultures, we must consider the ability of such "ex-competitor" flies to give rise to progeny in the next generation. It might, for example, be the case that the vg ex-competitors have a very low fertility as compared with the $O r$ ex-competitors and that this low fertility would nullify the competitive advantage of vg. Similar considerations apply to the other competitive situations.

In order to obtain ex-competitors in sufficiently large numbers, a single randomised block was set up, each tube containing 90 larvæ feeding on 8 rather than $6 \mathrm{ml}$. of medium corresponding to $0.7 \mathrm{mg}$. yeast per larva. The mixed cultures were of the $45 \mathrm{Or} / 45 \mathrm{dp}, 45 \mathrm{Or} / 45$ $v g$ and $45 d p / 45 v g$ types, each type being replicated 7 times. In addition, 2 tubes containing $90 \mathrm{Or}, 2$ containing $90 \mathrm{dp}$ and one containing 90 vg larvæ were included as a check on competition. We shall not give the results in detail but the average percentage survival rates were as follows:-

Pure Culture: Or $3^{8}$ per cent., $d p 43$ per cent., vg 22 per cent. Or/dp:

Or/og: $d p / v g$ : Or 12 per cent., $d p 5^{8}$ per cent., Or I I per cent.,

ug 35 per cent. $d p 39$ per cent., vg 30 per cent.

Thus the familiar competitive pattern emerged once again. The next step was to mate a random sample of male and virgin female ex-competitors in single pairs, $O r$ with $O r, d p$ with $d p$, and $v g$ with $v g$. In the case of $O r$, where comparatively few ex-competitors emerged, 20 single pairs were made up, Io from $O r$ which had been competing 
with $d p$ and Io from $O r$ which had been competing with $v g$. For the other two lines, 40 pairs were made up in each case, 20 for each of the competive situations. Each pair was placed in a tube containing normal oatmeal medium and live yeast. The tubes were placed in the incubator in a single randomised block and the flies allowed to produce their maximum number of progeny.

Out of $20 \mathrm{Or}$ matings, only 3 gave rise to any progeny. Seven out of $40 \mathrm{dp}$ and $\mathrm{i} 8$ out of $40 \mathrm{vg}$ matings were fertile. The $2 \times 3$ contingency $\chi_{[2]}^{2}=8 \cdot 84, \mathrm{P}=2-\mathrm{I}$ per cent. Thus the fertilities show a direct correspondence with the competitive abilities.

The situation is a little more complicated when we consider the actual numbers of progeny airising from these matings, because, as

TABLE II

Results of single pair crosses of ex-competitors

\begin{tabular}{|c|c|c|c|c|c|c|}
\hline \multirow{2}{*}{ Line } & \multirow{2}{*}{$\begin{array}{l}\text { Culture } \\
\text { from } \\
\text { which } \\
\text { derived }\end{array}$} & \multicolumn{2}{|c|}{ No. of crosses } & \multirow{2}{*}{$\begin{array}{l}\text { No. of progeny in individual fertile } \\
\text { crosses }\end{array}$} & \multirow{2}{*}{$\begin{array}{l}\text { Total } \\
\text { progeny }\end{array}$} & \multirow{2}{*}{$\begin{array}{l}\text { Mean progeny } \\
\text { per fertile } \\
\text { mating }\end{array}$} \\
\hline & & Fertile & Sterile & & & \\
\hline $\begin{array}{l}\text { Or } \\
\text { Or }\end{array}$ & $\begin{array}{l}\text { Or/dp } \\
\text { Or/vg }\end{array}$ & $\begin{array}{l}1 \\
2\end{array}$ & $\begin{array}{l}9 \\
8\end{array}$ & $\begin{array}{ll}90 & \\
3^{6} & 39\end{array}$ & $\begin{array}{l}90 \\
75\end{array}$ & $55^{\cdot 0}$ \\
\hline$\frac{d p}{d p}$ & $\begin{array}{l}d p / O r \\
d p / v g\end{array}$ & $\begin{array}{l}4 \\
5\end{array}$ & $\begin{array}{l}16 \\
15\end{array}$ & $\begin{array}{llllll}87 & 120 & 110 & 95 & \\
49 & 101 & 121 & 94 & 75\end{array}$ & $\begin{array}{l}4^{12} \\
44^{\circ}\end{array}$ & 947 \\
\hline $\begin{array}{l}v g \\
v g\end{array}$ & $\begin{array}{l}v g / O r \\
v g / d p\end{array}$ & $\begin{array}{r}10 \\
9\end{array}$ & $\begin{array}{l}10 \\
11\end{array}$ & $\begin{array}{rrrrrrrrrr}32 & 56 & 63 & 42 & 63 & 34 & 97 & 70 & 76 & 55 \\
5^{6} & 81 & 18 & 94 & 107 & 39 & 62 & 97 & 40 & \end{array}$ & $\begin{array}{l}588 \\
594\end{array}$ & $62 \cdot 2$ \\
\hline
\end{tabular}

will be seen, the average number of progeny per fertile mating is considerably higher in $d p$ than in the other two lines. The results are given in table II.

Irrespective of the number of progeny per fertile mating, we must assess the fitness of a line by the total number of progeny produced by a given number of matings, fertile and infertile alike. We must double the total progeny for $O r$, since these are derived from only 20 matings, whereas the $d p$ or $v g$ results are based on 40 matings each. This gives

$$
\begin{aligned}
& \text { Or } \mathrm{S}_{1}=330 \\
& d p \mathrm{~S}_{2}=852 \\
& \text { vg } \mathrm{S}_{3}=1182
\end{aligned}
$$

so that despite the differences in the numbers of progeny, the fitnesses are in the same order as the fertilities. To test the significance of these results, we note that if $T$ is the total output of progeny from a given line, then $\mathrm{T}$ has variance.

$$
\mathrm{V}(\mathrm{T})=\underset{r}{\mathscr{E}}[\mathrm{V}(\mathrm{T} \mid r)]+\underset{r}{\mathrm{~V}}[\mathscr{E}(\mathrm{T} \mid r)]
$$


where $r$ is the number of fertile matings and $\mathrm{V}(\mathrm{T} \mid r)$ is the variance of $\mathrm{T}$ conditional on $r$ of the matings being fertile. Hence we estimate $\mathrm{V}(\mathrm{T})$ as

$$
r \mathrm{~V}(x)+\bar{x}^{2} n p q
$$

where $\bar{x}$ is the mean number of progeny per fertile mating, $\mathrm{V}(x)$ is the variance of the number of progeny of fertile matings, $p$ is the proportion of matings which are fertile and $q=\mathrm{I}-p$. The various estimates of $\mathrm{V}(x)$ given by the different groups of crosses prove to be homogeneous and on pooling give a combined estimate for $V(x)$ of $5^{8} 7^{\circ} \mathrm{o}$ for $25 \mathrm{~d} . \mathrm{f}$. The values of $\mathrm{V}(\mathrm{T})$ are then easily calculated. Since our estimate of $\mathrm{V}(x)$ has 25 d.f., we shall make no serious error in regarding our estimate of $\mathrm{V}(\mathrm{T})$ as a theoretical variance. For $d p$ and $v g$ these are equally $V\left(S_{2}\right)$ and $V\left(S_{3}\right)$ respectively, whereas $V\left(S_{1}\right)=4 V\left(T_{1}\right)$ since we have multiplied the $\mathrm{T}$ value for Or by 2 . Hence we obtain

\begin{tabular}{|c|c|c|}
\hline Line & $S$ & $\mathrm{~V}(\mathrm{~S})$ \\
\hline $\begin{array}{l}O r \\
d p \\
v g\end{array}$ & $\begin{array}{r}33^{\circ} \\
85^{2} \\
115^{2}\end{array}$ & $\begin{array}{l}37,899 \\
67,79^{1} \\
49,75^{8}\end{array}$ \\
\hline
\end{tabular}

The weighted mean of the $S$ 's is $\bar{S}=735 \cdot 37$. We then have, approximately

$$
\chi_{[2]}^{2}=\Sigma \frac{(\mathrm{S}-\overline{\mathrm{S}})^{2}}{\mathrm{~V}(\mathrm{~S})}=8 \cdot 54, \mathbf{P}=2 \text {-I per cent. }
$$

showing that there is a significant difference between the lines.

We may now make a comparison of the fitness of ex-competitors issuing from the same competitive situation. Thus for $\mathrm{Or} / \mathrm{dp}$ competi-

\begin{tabular}{|c|c|c|c|c|}
\hline Line & $\mathbf{S}$ & $\mathrm{V}(\mathbf{S})$ & $\chi_{[1]}^{2}$ & $\mathbf{P}$ \\
\hline $\begin{array}{l}O r \\
d p\end{array}$ & $\begin{array}{l}180 \\
412\end{array}$ & $\begin{array}{l}31,508 \cdot 0 \\
36,296 \cdot 8\end{array}$ & $0 \cdot 79$ & $5^{0-30}$ per cent \\
\hline
\end{tabular}
tion we have

for Orlog we have

\begin{tabular}{|c|c|c|c|c|}
\hline Line & $\mathrm{S}$ & $\mathrm{V}(\mathrm{S})$ & $\chi_{[1]}^{2}$ & $\mathrm{P}$ \\
\cline { 1 - 1 } $\begin{array}{c}\text { Or } \\
v g\end{array}$ & $\begin{array}{c}150 \\
388\end{array}$ & $\begin{array}{c}13,696 \cdot 0 \\
23,157 \cdot 2\end{array}$ & $5 \cdot 21$ & 5 5-2 per cent. \\
\hline
\end{tabular}

and for $d p \log$ we have

\begin{tabular}{|c|c|c|c|c|}
\hline Line & $\mathrm{S}$ & $\mathrm{V}(\mathrm{S})$ & $\chi_{[1]}^{2}$ & $\mathrm{P}$ \\
\hline $\begin{array}{c}d b \\
v g\end{array}$ & $\begin{array}{c}440 \\
594\end{array}$ & $\begin{array}{c}31,975 \cdot 0 \\
24,667 \cdot 2\end{array}$ & $0 \cdot 42$ & 70-50 per cent. \\
\hline
\end{tabular}


the $\chi^{2}$ s being calculated in the usual way as the square of the difference between the S's, divided by the variance of the difference. Thus for Or/vg competition, the vg ex-competitors are significantly fitter than the Or. In the other two cases, the differences are not significant.

We can conclude, therefore, that the competitive differences observed in earlier experiments are biologically meaningful, since there is no tendency for competitive advantages to be neutralised by poor fitness of ex-competitors derived from strongly competing larvæ. On the contrary, there is a tendency, which reaches significance in certain cases, for the stronger competitors to give rise to fitter adults than do the weaker competitors.

We have shown that a major component of such differences in fitness is the relative fertility of ex-competitor lines. Another possible component of differences in fitness would be differences in hatchability

TABLE 12

Hatchability of eggs produced by ex-competitors

\begin{tabular}{|c|c|c|c|}
\hline Line & Hatched & Failed to hatch & Total \\
\hline Or & 93 & 7 & \\
$d p$ & 113 & 7 & 100 \\
$v g$ & 122 & 8 & 120 \\
& & 130 \\
\hline
\end{tabular}

of eggs. Accordingly, mass matings of $O r$ with $O r, d p$ with $d p$ and $v g$ with vg ex-competitors were made up and a number of eggs collected. These eggs were transferred to petri dishes containing agar, incubated at $25^{\circ} \mathrm{C}$. and their hatchabilities scored after a period of 2 days. Results are in table 12.

$\chi_{[2]}^{2}=0.1322, P=95-90$ per cent., so that there is no evidence that differences in hatchability are contributing to the differences in fitness.

\section{COMPETITIVE ABILITY OF LARVE PRODUCED BY EX-COMPETITORS}

The ex-competitor flies in turn give rise to larvæ and in order to assess the long term effects of competition, it is desirable to ascertain whether these larvæ reproduce the normal competitive pattern. Accordingly, mass matings of ex-competitor flies of each line were made up, and allowed to lay eggs. Unfortunately, the relatively low fertility of ex-competitor flies made it impossible to collect a sufficiently large number of eggs in the usual 3-4 hours and it was necessary to leave the flies overnight in the laying tubes. The three lines of flies appeared to lay at about the same rate, however, and the eggs to hatch at about the same time in the three lines, so that it is unlikely that any serious error was introduced. At the same time, eggs were 
collected from flies reared on normal oatmeal medium. Larvæ were obtained in the usual way.

In order to compare the competitive pattern of larvæ derived from ex-competitor flies with those derived from " normal" flies, it was

TABLE I3

Adults emerging from 3-way tubes containing larve derived from normal and ex-competitor flies

\begin{tabular}{|c|c|c|c|c|c|c|}
\hline \multirow{2}{*}{ Replicate } & \multicolumn{6}{|c|}{ Source } \\
\hline & \multicolumn{3}{|c|}{ "Normal " flies } & \multicolumn{3}{|c|}{ Ex-competitor flies } \\
\hline $\begin{array}{l}\text { I } \\
2 \\
3 \\
4\end{array}$ & $\begin{array}{c}O r \\
7 \\
0 \\
4 \\
3\end{array}$ & $\begin{array}{l}d p \\
16 \\
14 \\
12 \\
13\end{array}$ & $\begin{array}{l}v g \\
17 \\
18 \\
12 \\
13\end{array}$ & $\begin{array}{l}\text { Or } \\
6 \\
9 \\
6\end{array}$ & $\begin{array}{l}d p \\
14 \\
22 \\
15\end{array}$ & $\begin{array}{l}\text { vg } \\
\text { I } 7 \\
\text { I9 } \\
\text { I I }\end{array}$ \\
\hline Total & 14 & 55 & 60 & 21 & $5^{1}$ & 47 \\
\hline Mean & 3.50 & I 3.75 & $15 \cdot 00$ & $7 \cdot 00$ & $17 \cdot 00$ & 15.67 \\
\hline
\end{tabular}

TABLE I4

Analysis of comparative yields of normal and ex-competitor flies under competition

\begin{tabular}{|c|c|c|c|c|c|c|c|}
\hline \multicolumn{3}{|l|}{ Item } & S.S. & d.f. & M.S. & V.R. & $\mathbf{P}$ \\
\hline \multicolumn{8}{|c|}{ Overall yield of tubes } \\
\hline $\begin{array}{l}\text { Between sources } \\
\text { Error }\end{array}$ & • & $\dot{.}$ & $\begin{array}{l}2 \text { I } 2 \cdot 668 \\
4 \text { I } 4 \cdot 245\end{array}$ & $\begin{array}{l}\text { I } \\
5\end{array}$ & $\begin{array}{r}212 \cdot 668 \\
82 \cdot 849\end{array}$ & $2 \cdot 57$ & 20-10 per cent. \\
\hline \multicolumn{8}{|c|}{ Between line comparisons } \\
\hline $\begin{array}{l}\text { Between lines } \\
\text { Lines X sources } \\
\text { Error }\end{array}$ & - & $\dot{\bullet} \cdot$ & $\begin{array}{r}2530 \cdot 520 \\
91 \cdot 969 \\
472 \cdot 050\end{array}$ & $\begin{array}{r}2 \\
2 \\
10\end{array}$ & $\begin{array}{r}\text { I } 265 \cdot 260 \\
45 \cdot 985 \\
47 \cdot 205\end{array}$ & $\begin{array}{c}26 \cdot 80 \\
<I\end{array}$ & $\begin{array}{l}<0 \cdot \text { I per cent. } \\
\text { Not significant }\end{array}$ \\
\hline
\end{tabular}

decided to set up 3-way competition tubes ( $30 \mathrm{Or} / 30 \mathrm{dp} / 30 \mathrm{vg}$ ), each containing $8 \mathrm{ml}$. of medium, as affording the widest basis of comparison. Shortage of larvæ precluded the setting up of more than 3 replicate tubes of larvæ derived from ex-competitors. For the "normal" larvæ, 4 replicate tubes were used. The 7 tubes were arranged in the incubator in a single randomised block. The results are in table 13 .

The observed numbers were changed to percentages and then transformed to angles in order to stabilise the variances. Since each replicate tube is a split plot, there will be two error mean squares in 
the analysis, one appropriate to testing whether the overall yield of a tube varies with source of larvæ and the other appropriate to comparisons between the lines. The Analysis of Variance is given in table 14 .

It is clear that the number of $O r, d p$ or $v g$ flies obtained does not vary with the source. We conclude that larvæ derived from excompetitors reproduce the normal competitive pattern.

\section{SUMMARY}

I. The three lines of flies under investigation differ in competitive ability, $v g$ being superior to $d p$ and $d p$ to $O r$. These competitive differences hold at all three food levels investigated.

2. Replacement of strong competitors by weak competitors in the initial composition of a mixed culture leads to increased viability of both competing lines.

3. If we assume that competition is mainly for food, it is possible from a knowledge of the yields in pure culture and in 2-way mixed culture to predict the result obtained when all three lines are competing with one another. This strongly suggests that competition is mainly for food.

4. These competitive differences cannot be ascribed to differences in hatching time, as the median hatching time is almost identical in the three lines.

5. When food is abundant, the viability of a given line is the same in mixed as in pure culture.

6. These foregoing results suggest that the differences of competitive ability between the three lines are of a fairly simple kind. Possibly they represent differences in feeding rate.

7. Adults emerging from competition tubes differ significantly in their fitness, as measured by the number of progeny per mating, from one line to another, $v g$ being the most fit, $d p$ intermediate and $O r$ the least. Larvæ derived from such adults reproduce the normal competitive pattern.

8. The last two results indicate that competitive ability, as measured in terms of the number of adults emerging in mixed culture, is a biologically meaningful concept.

\section{REFERENCES}

BAKKER, $\mathbf{x}$. I96r. An analysis of factors which determine success in competition for food among larvæ of Drosophila melanogaster. Archives $\mathcal{N}$ éerlandaises de Zoologie, $X I V, 2,200-281$.

BIRCH, L. C. I957. The meanings of competition. Amer. Nat., 9I, 5-18.

FINNEY, D. J. 1952. Probit Analysis. (2nd ed.). Cambridge University Press.

CLATWORTHY, J. N., AND HARPER, J. L. 1962. The comparative biology of closely related species living in the same area. V. J. Exp. Bot., 13, 307-324.

milNe, A. 1961. Definition of competition among animals. Symp. Soc. Exp. Biol., $X V, 40-6 \mathrm{r}$. 